\title{
Protein Renaturation
}

National Cancer Institute

\section{Source}

National Cancer Institute. Protein Renaturation. NCI Thesaurus. Code C18137.

The process of restoring the activity and quaternary structure of a native polypeptide through folding and conformational intermediates. 